unclosed in some of us for use? But one is sometimes met with the remark that, if these rudimentary and variable structures are useless, they are at any rate not injurious. But is it so? May they, and do they, not become injurious under disease or accident? There is the male mamma, for instance, which we have sometimes occasion to excise for disease. Whatever may be the law which regulates the evolution of the sexual organs, no "use" theory can account for the presence of that rudimentary organ. But the diverticulum is a possibly injurious structure not merely as a tissue, but in addition, specially, as forming, if I may use the word, a kind of trap, by lodgment or by strangulation. Thus we find that we have, whether we will or no, reached the conclusion that there are parts in the animal body which are not only useless but worse than useless because dangerous.

I do not see any reply to this in my critic's remark that it proves too much for the argument, that, for instance, because some people have died from wounds of the scalp, therefore the head might be dispensed with. For, however much the head may vary among us, it is not a rudimentary structure. No argument can affect the fact that the diverticulum is not only a useless structure, but worse than useless because dangerous. The object of putting it thus emphatically is both to establish and to call attention to the conclusion that there are such things in animal bodies as rudimentary structures, things which are of no use to the animal body which contains them, and which can be understood only by referring to other animal bodies in which they are in full play; and that we must therefore rise to higher conceptions of the mode in which these things are regulated. It was carefully stated in my paper that the consideration of such parts as the diverticulum does not carry us further than to clear away the old argument, but that, on taking a survey of rudimentary structures generally, we are led on to the cunciusion that the evolution hypothesis is the nore probable one in regard to the mode of origin of animal bodies.

The nature of the diverticulum and its sources of danger are well known to the readers of Meckel, Monro, Lawrence, Rokitanski, and Cruveilhier. I may be allowed to mention that nearly twenty years ago I rublished (Edin. Med. and Surg. Journal, April 1854) twenty cases of diverticulum, with a drawing of each. In three of these it was the cause of death, and I referred to some other cases in which it caused death as reported by previous writers. Anyone in Lonion who is desirous of seeing a case in which it caused death, may do so by looking into the museum of St. Bartholomew's Hospital. There is, I may mention, a diverticulum, at the usual place, in a subject now being dissected in my anatomical rooms. If my critic will come to Aberdeen I will show him a large collection of them, and also of specimens showing the various positions and conditions of the appendix vermiformis, and, indeed, many other interesting rudimentary structures and variations which, I infer, he has not yet sesn.

My critic's objection that such discussions are unnecessary, that the true theory will ultimately prevail from its own intrinsic value, might be urged against all discussion; and I differ from him very much if he thinks that the question does not require to be stirred among and by the teachers of human anatomy in this country. The cause of my little paper, in fact, was my having, not long before, heard a teacher of human anatomy, at a similar meeting, call in question the whole argument from rudimentary structures. I attributed no importance to my paper further than that, in bringing forward the diverticulum, it submitted an illustration for the argument which does not admit of cavil.

Aberdeen, Nov. 22 JOHN STRUTHERS

\section{The Atmospheric Telegraph}

WILL you permit one of your subscribers who is interes'ed in the credit of the English telegraphic system, to supplement your article of November 27 by a few remarks?

The distribution of telt graphic messages by means of air was introduced by Mr. Latimer Clark, and had been employed by the Electric Telegraph Company long before it was adopted either in Berlin or Paris.

The Times article of November 15 deals with the undertaking of the Pneumatic Despatch Company for the conveyance of parcels and goods, not messages. The writer incidentally mentions the transmission of messages, but scarcely seems to have been aware of the extent of the Lond:n message system.

If I might encumber your valuable space by stalistics, I could show that the pneumatic system of the Pustal Telegraphs, or even that of the Electric Telegraph Company at the time of the transfer of their undertaking to the State, will bear comparison, both as to extent and efficiency, with that of Paris, effective as the latter is.

The system is employed in Manchester, Liverpool, Birmingham, Glasgow, and Dublin. R. S. CULLEY

General Post Office, Nov. 29

Engineer-in-Chief of Postal Telegraphs

\section{SENSATION IN THE SPINAL CORD}

$T \mathrm{HE}$ principle which I endeavoured some years ago to get recognised as the directive principle of research in Nerve Physiology, was that everywhere identity of Tissue carried with it identity of physiological Property, and that similarity in the structure and connections of Organs involved corresponding similarity in Function. Although these premisses were almost truisms, the conclusion drawnthat all nerve-centres must have a common Property, and similar Functions - was too much opposed to the reigning doctrine, to find general acceptance. Especially was it resisted in its application to the functions of the Spinal Cord ; and this because of the two hypotheses current, namely, that Reflex Action did not involve Sensibility, and that the Brain was the sole Organ of the Mind. Following in the track so victoriousiy opened by Pfiuger. I brought forward what seemed to me decisive evidence of the sensational and volitional functions of the Spinal Cord; but this evidence has not been generally deemed conclusive by those whose verdict is authoritative. Neither in Germany nor in England have the majority of physiologists consented to regard the actions determined by the Spinal Cord in the absence of the Brain as sensitive actions.

This is not the place to examine the insufficiency of the evidence which is held to exclude sensation from Reflex Action, nor to exhibit the irrationality of the conception of the Brain as the Organ of Mind-which, as I have elsewhere said, is not more acceptable than would be the parallel conception of the Heart as the Organ of Life. The purpose of the present paper is restricted to the examination of the most striking experimental evidence against the sensational function of the Spinal Cord, which to my knowledge has hitherto been advanced. I had intended reserving the criticism for its appropriate place in the "Problems of Life and Mind," but an article by Mr. Michael Foster which has just appeared (Fournal of Anatomy and Physioloogy, November), on the Effects of rise of Temperature on Reflex Action, induces me to bring the subject before the readers of NATURE, in the hope that some of them may re-investigate it and record their results.

I will merely remark that the microscopic investigations which have recently been made with greatly in creased powers and better methods of preparation, have more and more confirmed my assertion of the histological identity of Spinal Cord and Brain. On the other hand the experiments of Goltz (Funciionen der Nervencentrendes Frosches, 1869, p. r28) seem to supply direct evidence against the identity of property ; and this evidence cannot be ignored.

Goltz observed that a frog, when place 1 in water the temperature of which is slowly raised towards boiling, manifests uneasiness as soon as the temperature reaches $25^{\circ} \mathrm{C}$, and becomes more and more agitated as the heat increases, vainly struggling to get out, and finally, at $42^{\circ}$ C., dies in a state of rigid tetanus. The evidence of feeling being thus manifested when the frog has its brain, what is the case with a brainless frog? It is absolutely the reverse. Quietly the animal sits through all the successions of temperature, never once manifesting uneasiness or pain, never once attempting to escape the impending death. "The spinal soul sleeps, perhaps; it takes no heed of the danger. One must waken it. I touch with acid the skin of its back in that part which is raised above the surface of the water. Swiftly and surely the hind paw is brought to bear on it, and the acid on the irritated spot is wiped away; then theleg resumes its comfortable position." 
The water grows hotter and hotter, but the brainless frog never moves, till, at $56^{\circ} \mathrm{C}$, it expires in a state of tetanus.

This contrast is assuredly marked enougb, and most readers will be disposed to admit that if the brainless animal can endure, without manifesting even uneasiness, what in the normal animal produces every sign of intense pain, the conclusion that the brainless animal feels nothing, and therefore that his Spinal Chord is not a sensational centre, is irresistible. This conclusion I altogether reject. Not that I question the facts, for I have verified their accuracy ; and $\mathrm{Mr}$. Foster, who has repeatedly verified them, only points to the new difficulty which they raise, namely, why the brainless frog is not excited to reflex action by the stimulus of hot water? It is, therefore, the interpretation of the facts to which attention must be drawn; and to make this complete, let me here note counter facts which my experiments presented.

The brainless frog is not insensible to the heat, unless the insensibility be gradually produced. If its foot be dipped into the hot water the leg is violently retracted; and if the whole or greater part of the body be immersed, the frog struggles veliemently, and rapidly passes into a state of tetanus. The difference between the behaviour of a normal frog and a brainless frog when suddenly immersed in very hot water is not greater than might reasonably be anticipated between animals uninjured and animals with one great sensitive centre removed.

These facts are substantially confirmed by the facts brought forward in Mr. Foster's paper. He also finds the legs of a decapitated frog withdrawn by reflex action, as soon as the temperature of the water reaches a little over $30^{\circ} \mathrm{C}$. "However slowly the water be heated, the feet are always withdrawn at a temperature of $35^{\circ}$ or earlier." But he observes that when the whole body is immersed and the water gradually heated, no movement, or only the very sightest spasm of the muscles of the legs takes place.

The point to which he draws attention is, that whereas the stimulus of hot water applied to the foot causes reflex aciion, applied to the whole leg or the whole body it causes none; his explanation is that the depressing influence of heat on the Spinal Cord destroys its reflex powers. This explanation seems to accord very well with ail his observations, but is not in accordance with the fact mentioned by Goltz of the frog's wiping away the acid which is dropped on its back; a fact clearly manifesting the presence of reflex sensibility.

It is this fact which I should urge against Goltz, and all who share his views. It proves, to my mind, that although the frog remains motionless in the heated water and shows no sign of pain from the stimulus of heat, this is assuredly not because Sensibility in general is gone, but simply because Sensibility to iemperature is gone. It is not neccssary to refer to the many well-authenticated cases of analgesia without anesthesia, of insensibility to pain or temperature without insensibility to touch ; I will parallel Goliz's case of the brainless frog suffering itself to be boilcd without moving, by the case of the frog with its brain and other nerve centres intact, allowing its legs to be burnt to a cinder without moving. In a paper read at the Aberdeen Meeting of the British Association, I brought forward some experiments on frogs after their skins had been wholly or partially removed. (There were small patches of skin left on the head wherewith to compare the effects of stimuli). These frogs assuredly had not lost their Sensibility; they responded, as usual, to any stimulus applied to the patches of skin which remained; and as these responses were the responses of animals in possession of a brain, no one would explain them away as mere reflexes. Yet these sensitive frogs allowed their flayed limbs to be pinched, pricked, cut, burnt with acids, and even burnt to a cinder with the flame of a wax taper, yet remained motionless under all these stimuli, though a touch on the patch of skin would make them wince or hop away.
I did not try the experiment of boiling one of these frogs, but who can deny that the insensibility they presented with their brains and without their skins, is even greater than that presented by brainless frogs with their skins? The point urged is that the frog without its brain is incapable of feeling the stimulus of hot water, which, when the brain is intact, is felt intensely ; and the conclusion drawn is that the spinal cord is not a sensational centre. But this point is blunted when we find that the frog is equally insensible to the heat, when its brain is intact and only the skin removed. Ought we to conclude that the skin is the sensational centre? The one conclusion would be as logical as the other.

Mr. Foster, who is only treating of the infuence of temperature, asks why the sensations and cerebral processes are not dulled in the same way as he supposes the spinal processes to be dulled by heat? "The answer," he says, "is that a less intense sensory impulse is needed to call forth a movement of volition, that is, a movement carried out by the encephalon, than an ordinary reflex action, that is, a movement carried out by the spinal cord alone. The water as it is being warmed suggests a movement to the intelligent frog long before it is able to call forth an unintelligent refex action. The very first movement of the frog, the removal of any part of his body out of the water, increases the effect of the stimulus; for the return of the limb to the water already warm gives rise to a stronger stimulus than contact with the water raised to the same temperature while the limb is still in it; and thus one movement leads to another and the frog speedily becomes violent. It is nearly the same with the brainless frog when a movement has for some reason or other been. started; only in the observations we have been dealing with this initial movement is wanting."

Let us compare the energetic movements of the normal frog and the absence of movement in the brainless frog, with the energetic movements of a waking man in a suffocating atmosphere, and the absence of movements in the sleeping or stupefied man in the same atmosphere, and all the phenomena are clear. The waking man and normal frog are alert and alarmed. The sleeping
man and brainless frog remain motionless. Instead of our being surprised at the brainless frog manifesting so little Sensibility when the gradually-increasing heat is threatening its existence, we ought to be surprised at its manifesting so much Sensibility as a thousand experiments disclose; especially when we see that if the heat be suddenly applied the Sensibility is manifested as equally energetic in normal and in mutilated frogs.

In conclusion, let it be observed that unnecessary obstacles are thrown in the way of rational interpretation when connotative terms such as Spinal Soul (Rückertmarksecle) are adopted. It is one thing to assign a general physiological Property, such as Sensibility, to the nervous centres; another thing to assign a term which is the abstract expression of the connexus of sensibilities, to any one centre. In saying that the Spinal Cord is a seat of sensation, it is not meant that it is the seat, nor that the sensations are specifically like the sensations of colour, of sound, of taste, of smell; but they are as like these as each of these is like the other.

GEORge HENRY LEWES

\section{THE ARTISTIC REPRESENTATION OF NATURE*}

$T H E$ late autumn of every year introduces to the public a large supply of gorgeous volumes, "got-up" in lavish fashion with handsome plates and lightly-written letter-press, which are generally spoken of as Christmas Books, and are intended to be the means for the material expression of the generous feelings which that season is * "The Life and Habits of Wild Animals." Illustrated by Designs by
J. Wolf. (Macmillan, I873.) 